\title{
PRECIPITATE-BASED SELECTIVE ION-SENSITIVE ELECTRODES. RECENT DEVELOPMENTS IN THEORY AND APPLICATIONS
}

\author{
E. Pungor and K. Tóth \\ Institute for General and Analytical Chemistry \\ Technical University Budapest, Hungary
}

\begin{abstract}
A number of new precipitate-based electrodes based for example on mixtures of metal chalcogenides, as well as enzyme electrodes and coated wire electrodes, are described. Their analytical application in the widest sense is reviewed for anions and cations.
\end{abstract}

\section{INTRODUCTION}

One year ago we reported on the recent development of precipitate-based ion-selective electrodes and came to the conclusion that further progress in the field can only be expected if the theoretical knowledge is extended. As the literature shows, this year the number of papers has increased and some interesting basic studies have also been reported.

Interest has turned to the potentiometric method in the last decade as indicated by Buck's review paper ${ }^{1}$ in which more than a thousand references are cited. This interest is partly a result of the development of ion-selective electrodes. Another review on ion-selective electrodes has been published by Koryta ${ }^{2,3}$ in which the theoretical considerations for the interpretation of the behaviour of various types of ion-selective electrodes are dealt with. It has more than 700 references. Moody and Thomas ${ }^{4}$ have written a valuable book on ion-selective electrodes, which is a very good introduction to the problems connected with the use of these sensors. In addition to these, several reviews which are partly intended to call attention to ion-selective sensors, and partly to summarize their application in automation, have appeared in various languages ${ }^{5-17}$.

We deal here only with the precipitate-based ion-selective electrodes. Since the middle of the sixties we have always emphasized that every electrode which works on the basis of a precipitate exchange reaction should be called a precipitate-based electrode. This is important for differentiating them from other types functioning on either acid-base, or complex, equilibria. Every kind of precipitate-based electrode has similar theoretical problems, which are to a great extent different from those of other types of electrodes. It is, therefore, unfortunate that in the literature the differentiation is usually made on the basis of such a theoretically unimportant parameter as the struc- 
ture of the electrode membrane, that is, whether it is prepared from a single crystal, pressed crystal or crystals embedded in a supporting matrix. However, we do not know what would be the most suitable expression for this type of electrode to avoid the present confusion in the literature.

In this lecture we have attempted to summarize the latest literature results from the standpoint of (a) theoretical problems ; (b) physicochemical application of electrodes: (c) new electrodes and (d) application of the electrodes to analytical purposes.

\section{THEORETICAL ASPECTS OF PRECIPITATE-BASED SELECTIVE ION-SENSITIVE ELECTRODES}

Recently the theoretical research on ion-selective electrodes has been concentrated first on selectivity problems, and further on the problems of buffers and on the exact determination of the end-point of titrations using ion-selective electrodes. An interesting approach to the selectivity problem was given by Simon and Wuhrmann ${ }^{18}$ who derived a theory which can be applied to every kind of ion-selective electrode. They used a simple model for the deduction. The most important assumptions are as follows : (i) the model is only one dimensional; (ii) there is no convection; (iii) the chemical standard potentials and the diffusion coefficients do not depend on the coordinates and time; (iv) the activities and concentrations are equal in the membrane phase; $(v)$ the concentration profile in the membrane is linear; and (vi) thermodynamic equilibrium is established on the surfaces of the membrane.

A general equation was derived under these conditions, at zero external current. The selectivity constants of various types of electrodes were also studied. The modified expression of the selectivity constant of precipitatebased electrodes is in agreement with the experimental findings and with our earlier theoretical results ${ }^{19}$.

The definition and the determination of the selectivity constant were discussed at a former conference held last year at Mátrafüred ${ }^{20}$. The participants decided to unify the method of $\mathrm{pK}_{i k}$ determination and discussed the special problem of the precipitate-based electrodes. This arises if the concentration ratio of the interfering and appropriate ions is higher than the reciprocal value of the selectivity constant or coefficient. The same problem was investigated by Moody and Thomas ${ }^{21}$, who discussed the selectivities of silver bromide. Vesely ${ }^{22}$ has studied the selectivity problems of the fluoride ion-selective electrode and assumed that instead of Butler's suggestion ${ }^{23}$, the hydroxide-fluoride ion-exchange equilibrium on the electrode surface is the potential-determining process when the hydroxide ion interferes. This interpretation is in agreement with the general ${ }^{24}$ equation given earlier for precipitate-based ion-selective electrodes.

The selectivity of the iodide selective electrode to perchlorate, nitrate etc. was studied by Moorhead ${ }^{25}$ who found a slight interference beyond that calculated from the salt-effect on the activity coefficient.

Evans $^{26}$ has commented on the paper of Fleet and Storp ${ }^{27}$ and deduced a diffusion barrier model for the cyanide membrane electrode based on silver iodide and silver sulphide. The equation contains the iodide and cyanide 
diffusion coefficients. Instead of the stoichiometric coefficient which gives the ratio of the cyanide and the iodide liberated during the silver cyanide complex formation, the author suggests using the product of the stoichiometric coefficient multiplied by the ratio of the diffusion coefficients.

The response-time of ion-selective electrodes is of theoretical importance ${ }^{28}$. In the case of the copper electrode, it was concluded that a first order reaction determines the response time.

Potman and Dahmen ${ }^{29}$ investigated the response of the silver sulphide electrode to mercuric ion. They found that mercury enters the silver sulphide membrane if the electrode is exposed to a solution containing mercuric ions. The mercuric ion response was found to be $60 \mathrm{mV}$ decade. The mercury built into the membrane is not affected by EDTA and gives the X-ray fluorescence signal without alteration. The authors suggest the formation of $[\mathrm{AgHgS}]^{+}$ions fixed in the crystal.

Beg and Pratays ${ }^{30}$ have investigated the membrane phenomena of a parchment-supported silver iodide electrode but it does not respond to halide.

\section{BUFFERS}

One of the most important practical problems is the selection of reference standards. Solutions prepared by weight are suggested as standards at higher concentrations. However, in this case it is necessary to know the exact value of the activity coefficient. A good example for preparing reference standards is that given for fluoride by Robinson, Duer and Bates ${ }^{31}$. In addition, TISAB, a total ionic strength adjusting buffer, is widely accepted at medium fluoride ion activities.

Heckel and Marsh $^{32}$ stated that ammonium carboxylate buffers in polar solvents are completely unsuitable for the determination of fluoride. Evans, Moody and Thomas ${ }^{33}$ discussed the problem of the carboxylic acid buffers and stated that they interfere below $10^{-4} \mathrm{M}$ of fluoride in aqueous solution. Heckel and Marsh ${ }^{32}$ recommend amino acids for preparing buffers. Amino acids form zwitterions, which react freely with protons and hydroxyl ions but to a much smaller extent with fluoride and lanthanum ions.

A precipitate-solution equilibrium has been used for the preparation of various ion-buffers ${ }^{34}$ such as chloride, bromide, iodide, fluoride and silver. The buffer consists of a saturated solution of the precipitate.

Metal buffers are of importance now that metal ion-selective electrodes have become available. Two ways have been suggested for the preparation of copper buffers ${ }^{35}$. The first is based on the complex-formation equilibrium of the metal with a ligand at a given ratio. The ligand is usually an anion of a weak acid and therefore the metal ion concentration can be determined from the $\mathrm{pH}$ of the appropriate $\mathrm{pH}$-buffer. The other way consists in adding a second metal ion to the buffer mentioned previously. In this case the concentration of the first metal ion is controlled by that of the second.

Copper buffers which contained mixed metal complexes were studied in detail by Blum and $\mathrm{Fog}^{36}$ in the range of $\mathrm{pCu}$ 4-15. Růžička and Hansen ${ }^{37}$ prepared cadmium buffers on the same principle using EDTA and NTA as ligands. 
For clinical purposes Durst, Staples and Paabo suggested sodium and chloride activity standards ${ }^{38}$. The preparation of concentration standards by a coulometric method was studied by Bailey and Pungor ${ }^{39}$. The method can only be applied in solutions of constant ionic strength, and only for such ions as can be generated with 100 per cent current efficiency.

It can be stated that even now such a buffer series is not generally available for $\mathrm{pX}$ as for $\mathrm{pH}$. This means that quite a lot of work should be done in this field, because such standards are fundamental to the correct application of ion-selective electrodes.

The standardization of electrodes is always connected with the problem of liquid junction potential because the uncertainty in its determination causes an error in potentiometric measurements. Baumann ${ }^{40}$ reported on the application of ion-selective electrodes to the determination of liquid junction potential using an iodide electrode in sodium perchlorate and perchloric acid mixtures containing iodide ions in low concentrations. The variation of the acid-salt ratio alters the liquid junction potential which is used for the calculation. In addition to this, the liquid junction potential can be excluded by the application of two different ion-selective electrodes in the sample, which contains the appropriate ions. The concentration of one of the appropriate ions is kept constant. For the measurements a symmetrical amplifier of high input impedance is suggested ${ }^{41}$.

The addition technique ${ }^{42}$ is superior to other direct potentiometric methods, because it eliminates the problem of the determination of liquid junction potentials, activity coefficients etc. There are two ways for the application of the methods; one is the standard addition method, while the second is the analate technique. The evaluation of the results is carried out either by calculation, or in the case of multiple addition by a computer. Karlberg has given the essential requirements for the use of a nomograph $^{43}$.

Buffle and coworkers discussed the errors of the Gran addition method in several papers ${ }^{44-46}$. The error is small if the concentration of the standard solution is close to that of the unknown sample, and if the slope of the electrode calibration curve is determined with a precision more than 98 per cent.

The end-point determination of potentiometric titrations is another interesting problem ${ }^{47}$. It has been emphasized that the interference of various ions is dominant at the end-point if the appropriate ion is in a relatively low concentration, because the end-point is not symmetrical. Schultz ${ }^{48}$ underlines that the application of the Gran plot technique solves the interference problem at the end-point, because the points selected are far from the equivalence point, and so the concentration ratios of the appropriate and interfering ions are more favourable. Carr ${ }^{49}$ investigated the effect of the complex equilibrium constant, the initial analate concentration and the ionic interference on the determination of the inflection point. He also states that the Gran plot method does not entail any serious error, but if the equilibrium constant and the initial concentration of analate decreases, or the ionic interference increases, then the titration error increases.

Selig applied the Gran plot method to the potentiometric determination of organic fluorine compounds after combustion using lanthanum salt as titrant $^{50}$. 


\section{APPLICATION OF ION-SELECTIVE ELECTRODES TO PHYSICOCHEMICAL INVESTIGATIONS}

In the last year, the use of ion-selective electrodes in physicochemical studies has increased. Covington and Thain suggested the fluoride electrode for the measurement of the dissociation constant of hydrogen fluoride as an undergraduate experiment ${ }^{51}$. Baumann investigated the tantalum fluoride complexes in $2 \mathrm{M}$ perchlorate at $25^{\circ} \mathrm{C}$ and calculated the stability quotient from mono- to hepta-fluorotantalates on the basis of the fluoride ion activity measured with a fluoride ion-selective electrode ${ }^{52}$.

Agarwal and Moremo studied the stability constants of aluminium fluoride complexes. The stability constants of four aluminium fluoro-complexes were determined successfully by the titration of aluminium nitrate with sodium fluoride at various ionic strengths ${ }^{53}$.

Hefter investigated the determination of the stability constants of mixed complexes such as $\mathrm{PbFCl}$ and $\mathrm{PbFBr}$. Using ion-selective electrodes with this method such mixed complexes can be studied which exist only in very limited concentration ranges ${ }^{54}$.

Complex studies have also been carried out by Heerman and Rechnitz ${ }^{55}$ in non-aqueous media such as acetonitrile. A copper ion-selective electrode was employed for the investigation of the copper halide complexes in acetonitrile. The $\beta$ values of the copper chloride, copper bromide, copper iodide and the thiourea-copper(I) complexes were calculated.

The use of membrane electrodes in flowing systems was discussed in detail by Thompson and Rechnitz ${ }^{56}$. They investigated kinetics of the formation of iron fluoride complexes and the effect of flow rate on the electrode response. It was found that the latter has no effect on the electrode response within the range $0.7 \mathrm{ml} \mathrm{s}^{-1}$. The authors suggested the use of ion-selective electrodes for following rapid solution reactions and furthermore for the simultaneous detection of several ions in the same reaction stream. The application of the electrodes in stopped-flow techniques was also recommended.

Knevel and $\mathrm{Kehr}^{57}$ used a chloride electrode for the investigation of the kinetics of the cyclization of the methylbis(chloroethyl)amine, at which chloride ion is liberated. The measurements were carried out with success and the authors suggest generally the application of ion-selective electrodes for such kinetic studies.

The bromide ion-selective electrode was used by Körös and Burger ${ }^{58}$ for the investigation of the Zhabotinsky-type oscillation reaction. The oxidation of the malonic acid with bromate using ceric ion as catalyst was followed in this way.

The ion-selective electrodes may possibly be used for the determination of single ionic activity coefficients. This can be done by the measurement of the temperature coefficient of electrodes in non-isothermal galvanic cells as suggested by Milazzo ${ }^{59}$. Preliminary work in this direction using halide and sulphide ion-selective electrodes has also been carried out ${ }^{60}$. 


\section{NEW ION-SELECTIVE ELECTRODES}

Besides theoretical investigations, research has been carried out on the development of new ion-selective electrodes. Although the number of papers published on novel electrodes in the last year is fairly large, the spectrum of the electrodes has not been much enlarged. Many papers discuss previously known electrodes, but they use a new technique in their preparation. Such techniques are the application of various sintering methods, or, in the case of heterogeneous electrodes, changing the supporting materials. However, it is unfortunate that electrode specification data is often determined by a variety of methods. For this reason the participants of the symposium on Ion-selective Electrodes at Mátrafüred ${ }^{61}$ agreed some appropriate methods for obtaining comparable experimental data.

The method of preparation of electrodes on a precipitate base has not changed much lately. The application of monocrystals has also been continued ${ }^{62,63}$. In addition to this, electrodes were developed on sintered crystal bases, while the heterogeneous electrodes have been prepared using other supporting materials. The coated wire electrodes suggested by Freiser and the electrode type called the 'Selectrode' have been further developed. At the same time the scope of coated surface electrodes has been enlarged recently. This type of electrode was introduced first by Guilbault.

\section{ALKALI- AND ALKALINE EARTH-ELECTRODES}

Besides the Simon potassium electrode prepared in a silicone rubber matrix ${ }^{64}$, a tetra-p-chlorophenylborate-potassium salt based PVC electrode was suggested by Davies et al. ${ }^{65}$ for potassium measurements. The authors investigated various potassium electrodes and stated that the PVC membrane and the PVC coated wire potassium electrodes show a good potassium response. The authors compare the PVC with the commercially available electrodes. A potassium micro-electrode was described by Vorobjev and Khitrov ${ }^{66}$.

A caesium electrode was prepared by Coetzee from caesium-12-molybdophosphate ${ }^{67,68}$. The caesium electrode does not show a Nernstian response, and its selectivity to various unicharged ions varies with the concentration. This interference is similar to that of ion-associated systems. The dynamic response of the electrodes is sluggish.

An alkaline earth metal ion-selective electrode ${ }^{69}$ was prepared by using an alkaline earth metal stearate single crystal doped with ions of ionic radii similar to those of the alkaline earth metal. Suitable cations for doping are $\mathrm{Ti}(\mathrm{IV}), \mathrm{La}(\mathrm{III}), \mathrm{Ag}^{+}, \mathrm{Na}^{+}$, and $\mathrm{Li}^{+}$. For calcium and magnesium measurements, calcium and magnesium fluoride membranes ${ }^{70}$ were also used, which contain fluorides of scandium, yttrium, bismuth or lanthanum in low concentration.

\section{ELECTRODES SENSITIVE TO HEAVY METAL IONS}

Electrodes for the measurements of heavy metal ions were prepared in various ways. For the preparation of the copper(II) ion-selective electrode, 


\section{PRECIPITATE-BASED ELECTRODES}

a specially prepared copper sulphide precipitate was incorporated in silicone rubber $^{71}$. The electrode shows a Nernstian response in the $\mathrm{pCu}=0-12$ range.

Copper(I) iodide embedded in PVC has also been used ${ }^{72}$ as an electrode material. The slopes of the electrode calibration curves prepared for $\mathrm{Cu}(\mathrm{I})$ and $\mathrm{Cu}(\mathrm{II})$ ions are not in accord with theory. Cadmium, lead, zinc, calcium, and magnesium slightly interfere with the electrode behaviour. The response time of the electrode is $10 \mathrm{~s}$ which is rather long in comparison with the copper electrodes $\left(R_{t}=30-40 \mathrm{~ms}\right)$.

Vesely, Gregor and Lindra ${ }^{73}$ suggested copper(I) selenide and silver selenide single crystals, polycrystals, or sintered crystals as electrode materials for copper determination.

An interesting sensor for copper measurement is chalcogenite glass ${ }^{74}$ containing 60 per cent selenium, 28 per cent germanium and 12 per cent antimony, doped with atomic iron. This electrode shows a redox sensitivity and the slope to copper(II) in the presence of potassium nitrate indicates a two-electron redox process. On the contrary, if the solution contains potassium chloride in the same range as potassium nitrate the slope indicates a one-electron process, because the presence of chloride stabilizes the copper(I) state.

A copper electrode for potentiometric titrations can be prepared by covering the surface of silver sulphide electrode with copper sulphide ${ }^{75}$ This method can be applied not only for copper, but also for the preparation of other heavy metal ion electrodes.

Silver sulphide and copper chalcogenides are suitable for electrode preparation after sintering ${ }^{76}$. Selenides and tellurides are used as chalcogenides. The electrode shows a Nernstian response for copper(II) ions down to $10^{-6} \mathrm{M}$. In the same way, it would be possible to prepare lead, cadmium, zinc, manganese, cobalt and nickel electrodes. However zinc, manganese, cobalt and nickel sulphides do not show an electrode response.

Vesely, Jensen and Nicolaisen ${ }^{77}$ have investigated the behaviour of the Crytur silver sulphide electrode and state that it is suitable for the measurement of silver. They have determined the selectivity constants of the electrode to copper, lead and hydrogen ions. The effect of the preparation of silver sulphide on the selectivity was marked.

A ceramic silver sulphide electrode was studied by Liteanu, Popescu and Ciovirnache $^{78}$, who claim that the homogeneous electrodes are superior to the heterogeneous ones. The ceramic electrode is selective not only to silver, but also to mercury ions.

Mascini and Liberti ${ }^{79}$ reported on a novel lead electrode made of lead sulphide and silver sulphide incorporated in polythene. For the measurement of lead, lead selenide and lead telluride are especially recommended ${ }^{80}$. The behaviour of pure chalcogenides was compared with that of the sintered mixture of silver sulphide and chalocogenides; the sintered electrodes showed a theoretical response in a wide concentration range, while the electrode behaviour of the pure chalcogenides was poor.

An electrode based on cadmium sulphide and silver sulphide has been suggested for the determination of cadmium. The precipitate was applied to the electrode surface as suggested by Rüžička and $\operatorname{Hansen}^{81.82}$ or it was 
made of sintered cadmium sulphide, silver sulphide and copper(I) sulphide according to Hirata and Higashiyama ${ }^{83}$. In both cases a detailed discussion has been given on the preparation of the electrode material. The resistance of the ceramic electrode is relatively low.

A lead sulphide and silver sulphide based electrode was prepared by Gordievsky and coworkers ${ }^{84}$ who have investigated the optimum composition of the electrode. A similar system for cadmium was also studied. The selectivity of the electrodes to some interfering ions was investigated.

Vesely, Gregor and Jindra ${ }^{73}$ have suggested a mixture of lead sulphide and lead telluride for obtaining a good lead electrode.

A very interesting way has been suggested by Weiss ${ }^{85}$ for obtaining heavy metal electrodes. For this purpose the silver iodide based electrode was used and a non-Nernstian response was obtained for gold in the range pAu $5-8$ at low $\mathrm{pH}$ values. The gold exchanges with the silver iodide precipitate and the gold(III) iodide complex formed then decomposes to gold(I) iodide and iodine. The Aul produced does not give a gold response so regeneration of the surface is necessary. This can be carried out by immersing the electrode in potassium iodide which forms gold iodide complexes.

An iron(III) electrode can be prepared ${ }^{74}$ also on chalcogenite glass base by doping it with atomic iron, cobalt or nickel. The electrode measures the iron(III) concentration in the presence of iron(II).

\section{ANION-SELECTIVE ELECTRODES}

The silver sulphide has been suggested ${ }^{77}$ for the measurement of sulphide and cyanide ions. The slope of the calibration curve is $103 \mathrm{mV} / \Delta \mathrm{pCN}$.

For the measurement of thiocyanate, Mascini ${ }^{86}$ suggested a silver thiocyanate based electrode. The silver thiocyanate was embedded in a thermoplastic material and the electrode was used in nonaqueous media and also for studying complex equilibria.

A barium chromate-silicone rubber electrode responsive to chromate has been used as an indicator electrode in a precipitation titration ${ }^{87}$.

A sulphate-selective electrode ${ }^{88}$ comprising $32 \mathrm{~mol} \% \mathrm{Ag}_{2} \mathrm{~S}, 31 \mathrm{~mol} \%$ $\mathrm{PbS}, 32 \mathrm{~mol} \% \mathrm{PbSO}_{4}$, and $5 \mathrm{~mol}_{\%} \mathrm{Cu}_{2} \mathrm{~S}$ showed a Nernstian response to sulphate in the range of $\mathrm{pSO}_{4} 2-4$.

For obtaining a perchlorate selective electrode Sharp ${ }^{89.90}$ used p-phenylene diamine derivatives and $o$-toluidine as radical cations which form salts with perchlorate. The electrode behaviour was interpreted in terms of acid-base and redox equilibria. A better perchlorate electrode was obtained by using $N$-ethylbenzothiazol-2,2-azine as radical.

Hussein, Storp and Guilbault ${ }^{91}$ applied a cyanide electrode composed of 1:1 silver iodide and silver sulphide for measuring the rhodanase activity in flowing system. The rhodanase enzyme catalyses the reaction of cyanide with thiosulphate and the reduction in cyanide concentration is measured. A similar problem was investigated by Llenado and Rechnitz $z^{\mathbf{9 2 . 9 3}}$ who studied the behaviour of $\beta$-glucosidase in detail. For this a cyanide ionselective electrode was used. The method was about 30 times more rapid than the fluorimetric technique.

The preparation of various membrane electrodes was discussed by 
Banke ${ }^{94,95}$ who used silver chloride or silver iodide pressed pellets covered with the appropriate sensing compound by vapour deposition.

A capillary system for clinical investigations which can be used successfully for blood analysis was elaborated by Havas ${ }^{96}$.

\section{APPLICATION OF THE ELECTRODES FOR ANALYTICAL PURPOSES}

The ion-selective electrodes have found wide application in analytical chemistry. They have been used in clinical and biochemical analysis, industrially, for example in the sugar and leather industries, for soil analysis in agriculture, in the analysis of ores, in environmental analysis, and as detectors in chromatography. It is rather difficult to give a simple survey of their applications since the field is very wide.

The fluoride electrode is still the most commonly used electrode. Bronstein and Manning ${ }^{97}$ applied the fluoride electrode in melts and stated that the electrode gave thermodynamic data.

Frant ${ }^{98}$ used the electrode for indicating the fluoride activity in chromium plating baths. The effects of various components of the bath on the amount of fluoride measured was investigated.

The determination of fluoride in silicate rocks was investigated by Jägner and Pavlova ${ }^{99}$. The silicate rocks were decomposed by sintering at $900^{\circ} \mathrm{C}$ with sodium carbonate and zinc oxide. The sintered cakes were eluted with a sodium carbonate solution. For evaluation of the results the standard addition technique was used.

Peters and Ladd ${ }^{100}$, who used a fluoride electrode for the determination of fluoride in ores, fluorspar, opal glass, phosphate rocks etc., gave a detailed description of the method and compared it with previously used procedures such as Willard and Winter's ${ }^{101}$.

Palmer ${ }^{102}$ investigated the application of the fluoride electrode to the determination of fluoride in the aluminium industry for aluminium fluoride, cryolite, fluorosilicate analysis etc. The interference of calcium, aluminium, silica and hydroxide was eliminated by adding an ammoniacal sulphosalicylate and EDTA solution. It was stated that the sulphosalicylate prevents the interference of iron(III), uranium(vI), beryllium, zirconium and titanium.

$\mathrm{Kubec}^{103}$ used the fluoride electrode with success in natural phosphate analysis and for the control of the production of superphosphate, sodium phosphate, and phosphoric acids.

In plants a very low amount of fluoride was determined after mineralization either by using sodium carbonate ${ }^{104}$ or sodium hydroxide ${ }^{105}$. The $\mathrm{pH}$ of the solution obtained was adjusted at 5.2 with acetic acid ${ }^{105}$ or TISAB ${ }^{104}$ and the fluoride was determined by the standard addition technique.

Louw and Richards ${ }^{106}$ studied the possibility of fluoride determination in sugar cane and the elimination of interference from silicon, aluminium and iron. This can be done by fusing the sample with a mixture of sodium carbonate and zinc oxide. After leaching with deionized water the residual trace elements were complexed by citrate.

The fluoride electrode is of importance also in clinical analysis. Tušl ${ }^{107}$ reported on the determination of urinary fluoride. His work showed that 
the pretreatment of urine with perchloric acid, as suggested by Cernik, Cooke and Hall ${ }^{108}$ is necessary only if the sample contains covalently bound fluoride.

The fluoride content of tooth enamel ${ }^{109}$ can be determined after dissolving the material in perchloric acid and buffering with sodium citrate. The method is very sensitive and a sample taken from the surface of only one tooth is sufficient.

The micro-determination of fluoride in organic materials was the subject of some papers. Rittner and $\mathrm{Ma}^{110}$ fused the organic material with sodium peroxide in a micro-bomb and then treated it with TISAB. The fluoride content was measured directly. Interference from phosphate and boron was overcome.

Helešic ${ }^{111}$ treated fluoride-containing organic samples before the measurements using the Schöniger method. The fluoride was titrated with lanthanum nitrate in 80 per cent ethanol. Lanthanum, gadolinium, praseodymium and ytterbium were also used as titrant. The titrations were carried out in neutral solution.

Terry and Casler ${ }^{112}$ investigated the determination of organometallic fluoride. The sample was placed in a combustion flask charged with oxygen and containing TISAB solution. After ignition the fluoride was measured with the direct method. Boron interfered.

Fluoride traces in materials can be extracted with triphenyl antimony(v) dichloride dissolved in carbon tetrachloride from solutions containing cyclohexane diamine tetraacetate ${ }^{113}$. In this way the influence of other metal ions was eliminated. The organic phase was then re-extracted with aqueous alkali and the aqueous phase treated with carbon tetrachloride to eliminate the antimony(v) reagent. The fluoride was determined with the direct method down to $10^{-6} \mathrm{M}$. Considering that during the extraction procedure an enrichment is achieved, the lower detection limit lies at $10^{-8} \mathrm{M}$ fluoride.

Sub-nanomole amounts of fluoride were determined by Heckel and Marsh $^{32}$ in polar organic solvents containing 5 per cent water. In the titration method lanthanum nitrate was used as titrant while amino acids proved to be very good buffers in the polar solvents used.

Warner and Bressan ${ }^{114}$ investigated the application of the fluoride electrode to fluoride determination below p.p.b. level, in rain, fog and aerosols. The method is based on the measurement of the rate of the potential change measured between the unknown and the standards, the concentration of which is close to that of the sample.

A very sensitive gas-chromatographic detector ${ }^{115}$ was built also using a fluoride electrode for investigating fluorine-containing organic compounds. In the case of fluorobenzene the lower detection limit lies at about $5 \times 10^{-11} \mathrm{M}$. The response time of the detector is about a few seconds. Theorganic compounds were separated on a gas-chromatographic column, with hydrogen as carrier gas, and the gas leaving the column was passed through a platinum tube at $1000^{\circ} \mathrm{C}$. The decomposition of the compound results in hydrogen fluoride which is absorbed in a buffer solution flowing at a constant rate.

Potman and Dahmen ${ }^{29}$ determined the chlorine and bromine content of halogenated volatile organic compounds. The vapours were burnt in an 


\section{PRECIPITATE-BASED ELECTRODES}

oxygen stream over platinum and quartz and the resulting gases were absorbed in concentrated acetic acid containing mercuric halides and hydrogen peroxide. The halide was titrated with mercury.

Duff and Stuart ${ }^{116}$ determined the chloride content of calcium phosphate. After dissolution in a mixture of perchloric and citric acids the $\mathrm{pH}$ was adjusted to about 2.5 and the fluoride content was measured with a direct potentiometric method.

Conrad ${ }^{117}$ determined chloride and cyanide in millimole amount using a titration procedure with silver nitrate.

Membrane electrodes are suitable for the determination of halides and the stability constants of halide complexes in aqueous solutions ${ }^{118}$.

Simonyi and Kálmán ${ }^{19}$ investigated the hydrolysis of aluminium chloroisopropylate by means of a chloride electrode.

A chloride electrode was used ${ }^{120}$ for the determination of chloride in pesticides after combustion using the Schöniger method. The bromide content of biological fluids was investigated by Degenhart et al. ${ }^{121}$ They measured the potential difference between two blood samples, one taken before, and one taken after bromide administration, and used it to calculate the bromide content of the blood.

Halides have been determined by potentiometric titration in acetonitrile using a chloride electrode or the classical silver electrode. It was found that the silver electrode is superior to the chloride ion-selective electrode, except when the solution contains oxidizing compounds or strong acids. However, the difference in the errors cannot be interpreted easily ${ }^{122}$.

The halide electrodes have been used earlier in water analysis. The chloride electrode has also been used in the last year for the determination of the chloride content of sea water ${ }^{123}$.

Chloride was determined ${ }^{124}$ in brewing water with various methods including the membrane electrode method. It was concluded that the brewing water contained both ionised and nonionised chloride.

The applicability of the chloride electrode for measuring the chloride content of polluted air was investigated ${ }^{125}$ by first pumping the air through an absorbent.

Cyanide and iodide were determined in the same solution using an iodide electrode in waters and various chemicals at very low levels ${ }^{126}$.

Silver halide membrane electrodes ${ }^{127}$ were applied to the determination of cyanide in photographic developing solutions. The silver deposition on the surface of the membrane was prevented by the addition of EDTA and NTA in citric acid solution.

Komiya $^{128}$ suggested a bromide electrode for the direct and indirect potentiometric determination of thiocyanate.

Frant, Ross and Riseman ${ }^{129}$ devised an excellent method for the determination of very low amounts of cyanide using the Gran plot technique. The interference of various metals forming complexes with cyanide was overcome by the addition of EDTA.

\section{DETERMINATION OF OTHER ANIONS}

The study of organic sulphur compounds ${ }^{30}$ gave interesting results as regards the determination of the reaction path. 
Trace amounts of sulphur can be determined ${ }^{131}$ in petroleum using a lead ion-selective electrode. The sample was burnt in an oxyhydrogen burner and the product absorbed in nitrite solution. The excess of nitrite was destroyed by boiling. After cooling the titration was carried out with lead perchlorate in a 50 per cent dioxane-water mixture.

Niklas-Salminen ${ }^{132}$ investigated sulphide determination in leather by various methods, and found that potentiometric titration with silver nitrate titrant using a sulphide indiator electrode is the only one suitable which can be carried out with sufficient accuracy.

The sulphide ion-selective electrode has found application in the measurement of the formation constant of $\beta$-cyanoalanine ${ }^{133}$.

One of the most difficult problems is the determination of sulphate. Harzdorf ${ }^{134}$ suggested the determination of sulphate by titration with barium perchlorate at $\mathrm{pH} \mathrm{5-7} \mathrm{in} \mathrm{dioxane-water} \mathrm{mixture.} \mathrm{The} \mathrm{indicator}$ electrode is a lead ion-selective electrode. The system can be used for the determination of lead-containing organic materials. The measurements can be carried out down to $5 \times 10^{-7} \mathrm{M}$. The same method can also be employed for the determination of barium and strontium.

Another method for sulphate determination was elaborated by Jasinsky and Trachtenberg ${ }^{135}$ with an iron(III)-sensitive electrode. The basis of the determination is that iron(III) is complexed by sulphate. From the free ferric concentration determined, the sulphate content can be calculated.

Sulphate was determined in soil extracts by potentiometric titration using a lead ion-selective electrode as indicator ${ }^{136}$.

\section{METAL DETERMINATIONS}

Ion-selective electrodes were first used for the determination of anions. In the last year only some metal determinations have been carried out by the application of ion-selective electrodes, for example, the ceramic silver sulphide electrode for the determination of silver ${ }^{137}$ and the silver sulphide based silver electrode in fixing baths ${ }^{138}$. The determination of silver in electroplating baths was investigated by Tobias ${ }^{139}$.

Measurement of copper with EDTA and tetraphenyl borate titrant was carried out by Nomara and Nakagawa ${ }^{72}$. The same authors have used the copper electrode as sensors in ion-exchange chromatography. Lamm, Hansen and Rúžička ${ }^{140}$ reported on the application of a copper electrode for determining copper in soil.

\section{CONCLUSION}

It can be concluded that the theory of precipitate-based electrodes has not developed to a great extent in the last year.

Most work was done on the application of electrodes for physicochemical and analytical purposes, in connection with which electrode standardization was studied. However, the large number of review papers suggests that interest is focused on the field of electrochemistry.

The precipitate-based ion-selective electrodes have become favoured by the analysts. Their application in many fields is spreading. 


\section{PRECIPITATE-BASED ELECTRODES}

However, as we have stated previously ${ }^{47}$, the most important work still to be done is to acquire a deeper knowledge about the mechanism of the reactions taking place at the electrode surface. This seems very important not only in the elucidation of the response mechanism of the electrode but also in finding ways for preparing novel electrodes selective to different ions.

\section{ACKNOWLEDGEMENT}

We express our sincere thanks to Dr A. Páll-Hrabeczy, to whom we are greatly indebted for her valuable contribution to this work.

\section{REFERENCES}

1 R. P. Buck. Anal. Chem. 44, 270 R (1972).

2 J. Koryta. Anal. Chim. Acta 61, 329 (1972).

3' J. Koryta. Iontové Selektivni Membránové Electrody, Academia Praha, 1972.

4 G. J. Moody and J. D. R. Thomas. Selective Ion-Sensitive Electrodes, Merrow (1971).

5 H. Baumang. Münchner Beitrag Abwasser-, Fisch-, Flussbiol. 19, 271 (1971).

6 D. C. Cornish and R. J. Simpson. Meas. Contr. 4, 308 (1971).

7 F. Oehme. Dechema Monogr. 67, 727 (1971).

8 N. Ishibashi and Nobuhiko. Kagaku Kogyo 23, 795 (1972).

9 F. P. Ijsseling. Chem. Techn. (Amsterdam) 27, 233 (1972).

10 Th. B. Warner. J. Mar. Technol. Soc. 6, 24 (1972).

11 J. T. Clerc, G. Kahr, E. Pretsch, R. P. Scholer and H. R. Wuhrmann. Chimia 26, 287 (1972).

12 S. H. Omang. Kjemi 32 12 (1972).

13 Cl. Gavach. Bull. Soc. Chim. Fr. 3395 (1971).

14 C. Liteanu and I. C. Popescu. Studii Cerc. Chim. 20, 73 (1972).

15 A. Hulanicki. Chemia analit. 17, 217 (1972).

16 E. Pungor and K. Tóth. Ion Selective Sensors, Analytical Chemistry 3. 521, Butterworths (1972).

17 K. Sakai. Keiso 15, 64 (1972)

18 H-R. Wuhrmann. Diss Nr. 4805 ETA Zürich, 1972.

19 K. Tóth and E. Pungor. Anal. Chim. Acta 47, 291 (1969).

20 Ion Selective Electrodes. Akadémiai Kiadó, Budapest, 1973.

21 G. J. Moody and J. D. R. Thomas. Talanta 18, 1251 (1971).

22 J. Vesely. Electroanal. Chem. 41134 (1973).

23 J. N. Butler. Ion Selective Electrodes, NBS No. 314, Washington, 1969.

24 E. Pungor. Anal. Chem. 39, 28A (1967).

25 E. D. Moorhead and W. Paul. J. Appl. Chem. Biotechn. 22, 441 (1972).

26 D. H. Evans. Anal. Chem. 44, 875 (1972).

27 B. Fleet and H. von Storp. Anal. Chem. 43, 1575 (1971).

28 K. Tóth. Ion Selective Electrodes, Akadémiai Kiadó, p. 145 (1973).

29 W. Potman and E. A. M. F. Dahmen. Mikrochim. Acta Wien, 303 (1972).

30 M. Aijaz Beg and S. Pratap. J. Electroanal. Chem. 36, 349 (1972).

31 R. A. Robinson, W. C. Duer and R. G. Bates. Anal. Chem. 43, 1862 (1972).

32 E. Heckel and P. F. Marsh. Anal. Chem. 44, 2347 (1972).

33 P. A. Evans, G. J. Moody and J. D. R. Thomas. Lab. Practice 20, 644 (1971).

34 J. Havas, M. Kaszás and M. Varsányi. Hung. Sci. Instr. 25, 23 (1972).

35 F. H. Hansen, C. G. Lamm, and J. Rủžička. Anal. Chim. Acta 59, 403 (1972).

36 R. Blum and H. M. Fog. J. Electroanal. Chem. 34, 485 (1972).

37 J. Růžička and E. H. Hansen. Anal. Chim. Acta 63, 115 (1973).

38 R. A. Durst, B. R. Staples and M. Paabo. Experiatia Suppl. No. 18, 275 (1971).

39 P. L. Bailey and E. Pungor. Ion Selective Electrodes, Akadémiai Kiadó, Budapest, 1973, p. 167.

40 E. W. Baumann. J. Electroanal. Chem. 34, 238 (1972).

41 M. J. D. Brand and G. A. Rechnitz Anal. Chem. 42, 616 (1970).

42 R. A. Durst. Mikrochim. Acta 3, 611 (1969). 


\section{E. PUNGOR AND K. TÓTH}

43 Bo Karlberg. Anal. Chem. 43, 1911 (1971).

44 J. Buffle, N. Parthasarathy and D. Monnier. Anal. Chim. Acta 59, 427 (1972).

45 J. Buffle. Anal. Chim. Acta 59, 439 (1972).

46 N. Parthasarathy, J. Buffle and D. Monnier. Anal. Chim. Acta 59, 447 (1972).

47 F. Pungor and K. Tóth. Precipitate-Based Ion-Selective Electrodes, Analytical Chemistry 4. 105 Butterworths (1973).

48 F. A. Schultz. Anal. Chem. 43, 1523 (1971).

49 P. W. Carr. Anal. Chem. 44, 452 (1972).

50 W. Selig. Gran's plot. Appl. Anal. fluorine org. Comp. (1972).

51 A. K. Covington and J. M. Thain. J. Chem. Ed. 49. 554 (1972).

52 E. W. Baumann. J. Inorg. Nucl. Chem. 34, 687 (1972).

53 R. P. Agarwal and E. C. Moreno. Talanta 18, 873 (1971).

54 G. Hefter. J. Electroanal Chem. 39, 345 (1972).

55 L. F. Heermann and G. A. Rechnitz. Anal. Chem. 44, 1655 (1972).

56 R. I. Thompson and G. A. Rechnitz. Anal. Chem. 44, 300 (1972).

57 A. M. Knevel and P. F. Kehr. Anal. Chem. 44, 1863 (1972).

${ }^{58}$ E. Körös and M. Burger. Ion Selective Electrodes, Akadémiai Kiadó Budapest, 1973, p. 191.

59 G. Milazzo. Ion Selective Electrodes, Akadémiai Kiadó, Budapest, 1973, p. 115.

${ }^{60}$ E. Lindner, K. Tóth and E. Pungor. Ion Selective Electrodes, Akademiai Kiadó, Budapest, 1973, p. 205.

61 Ion Selective Electrodes. Akadémiai Kiadó, Budapest, 1973, p. 271.

${ }^{62}$ H. Adametzova and J. Gregor. Chem. Prum. 21, 506 (1971).

${ }^{63}$ D. Weiss. Chem. Listy 65, 1091 (1971).

${ }^{64}$ J. Pick, K. Tóth. M. Vašak, E. Pungor and W. Simon. Ion Selective Electrodes, Akadémiai Kiadó, Budapest, 1973, p. 245.

65 J. E. W. Davies, G. J. Moody. W. M. Price and J. D. R. Thomas. Lab. Practice 22, 20 (1973).

66 L. N. Vorob'ev and Yu. A. Khitrov. Fiziol. Rast. 18, 1054 (1971).

${ }^{67}$ C. J. Coetzee and A. J. Basson. Anal. Chim. Acta. 56, 321 (1971).

${ }^{68}$ C. J. Coetzee and A. J. Basson. Anal. Chim. Acta. 57, 478 (1971).

69 P. Pauline. U.S. Patent No. 3649568. (1972) C.A. 76, 148523 (1972).

${ }^{70}$ M. G. Farren. U.S. Patent No. 3657093. (1972) C.A. 77. 013710W (1972).

71 J. Pick, K. Toth and E. Pungor. Anal. Chim. Acta. 61, 169 (1972).

72 T. Nowara and G. Nakagawa. Bunseki Kagaku 20, 1570 (1971).

${ }^{73}$ J. Vesely, J. Gregor and J. Jindra. Czech Patent No. 143 144. (1971) C.A. 77, 069 793t (1972).

${ }_{74}$ C. T. Baker and I. Trachtenberg. J. Electrochem Soc. 118, 571 (1971).

75 T. Anfält and D. Jagner. Anal. Chim. Acta 56, 481 (1971).

${ }^{76} \mathrm{H}$. Hirata and K. Higashiyama. Talanta 19, 391 (1972).

77 J. Vesely, O. J. Jensen and B. Nicolaisen. Anal. Chim. Acta 62, 1 (1972).

${ }^{78}$ C. Liteanu, I. C. Popescu and V. Ciovirnache. Talanta 19, 985 (1972).

79 M. Mascini and A. Liberti. Anal. Chim. Acta 60, 405 (1972).

80 H. Hirata and K. Higashiyama. Anal. Chim. Acta 57, 476 (1971).

81 J. Rủžička and E. H. Hansen. Anal. Chim. Acta 63, 115 (1973).

82 J. Rủžička, C. G. Lamm and J. Chr. Tjell. Anal. Chim. Acta 62, 15 (1973).

${ }^{83}$ H. Hirata and K. Higashiyama. Z. Anal. Chem. 257, 104 (1971).

${ }^{84}$ A. V. Gordievskij, V. C. Sterman, A. Ja. Cirčenkov, N. I. Cavvin, A. F. Zukov and Ju. I. Uricove. Zh. Anal. Kh. 27, 2170 (1972).

85 D. Weiss. Z. Anal. Chem. 262, 28 (1972).

86 M. Mascini. Anal. Chim. Acta 62, 29 (1972).

87 U. O. Lukkari, E. J. Hakoila and H. K. Lukkari. Suom. Kemistilehti 45, 182 (1972).

${ }^{88}$ G. A. Rechnitz, G. H. Fricke and M. S. Mohan. Anal. Chem. 44, 1098 (1972).

${ }^{89}$ M. Sharp. Anal. Chim. Acta 61, 99 (1972).

90 M. Sharp. Anal. Chim. Acta 62, 385 (1972).

91 W. R. Hussein, L. H. von Storp and G. G. Guilbault. Anal. Chim. Acta 61, 89 (1972).

92 R. A. Llenado and G. A. Rechnitz. Anal. Chem. 44, 1366 (1972).

${ }_{93}$ R. A. Llenado and G. A. Rechnitz. Anal. Chem. 44, 468 (1972).

94 F. G. K. Baucke. Ger. Patent No. 2040200. (1972) C.A. 76, 107659t (1972).

95 F. G. K. Baucke. Ger. Patent No. 2059559. (1972) C.A. 77, 096250v (1972).

96 J. Havas. Kém. Közl. 37, 315 (1972).

97 H. R. Bronstein and D. L. Manning. J. Electrochem. Soc. 119, 125 (1972). 


\section{PRECIPITATE-BASED ELECTRODES}

98

Frant. Galvanotechnik 63, 745 (1972)

99 D. Jagner and V. Pavlova. Anal. Chim. Acta 60, 153 (1972).

100 M. A. Peters and D. M. Ladd. Talanta 18, 655 (1971).

101 H. H. Willard and O. B. Winter. Ind. Eng. Chem. Anal. Ed. 5, 7 (1933).

102 T. A. Palmer. Talanta 19, 1141 (1972).

103 Z. Kubec. Chem. Prum. 2, 564 (1971).

104 M. Hukushima, H. Hukushima and T. Kuroda. Bunseki Kagaku 2, 522 (1972).

105 R. L. Baker. Anal. Chem. 44, 1326 (1972).

106 C. W. Louw and J. F. Richards. .4nalyst 97, 334 (1972).

107 J. Tušl. Anal. Chem. 44, 1693 (1972).

108 A. A. Cernik, J. A. Cooke and R. J. Hall. Nature 227, 1260 (1970).

109 M. J. Larsen, M. Kold and F. R. van der Fehr. Caries Res. 6, 193 (1972).

110 R. C. Rittner and T. S. Ma. Mikrochim. Acta (Wien) 404 (1972).

111 L. Helešic. Collection Czech. Chem. Commun. 37, 1514 (1972).

112 M. B. Terry and F. Kasler. Mikrochim. Acta (Wien) 569 (1971).

${ }^{113}$ H. Chermette, C. Marfelet, D. Sandino, M. Benmalek and J. Tousset. Anal. Chim. Acta 59, 373 (1972).

114 Th. B. Warner and D. J. Bressan. Anal. Chim. Acta. 63, 165 (1973).

115 T. Kojima, M. Ichise and Y. Seo. Talanta 19, 539 (1972).

116 E. J. Duff and J. L. Stuart. Anal. Chim. Acta 57, 233 (1971).

117 F. J. Conrad. Talanta 18, 952 (1971).

118 M. Bartusek, J. Senkyr, J. Janošová and M. Polašek. Ion Selective Electrodes, Akadémiai Kiadó, Budapest, 1973, p. 173.

119 I. Simonyi and I. Kálmán. Ion Selective Electrodes, Akadémiai Kiadó, Budapest, 1973, p. 253.

120 L. Vajda and J. Kovács. Hung. Sci. Instr, 20, 31 (1971).

121 H. J. Degenhart, G. Abeln, B. Bevaart and J. Baks. Clin. Chim. Acta 38, 217 (1972).

122 G. Lemahien, C. Lemahien-Hodé and B. Résibois. Analusis 1, 110 (1972).

123 N. Ogata. Bunseki Kagaku 21, 780 (1972).

124 Y. Totsuka. Nippon Joso Kyokai Zasshi 67, 146 (1972).

125 M. Kertész-Sármger and J. Havas. Egészségtudomány 16, 77 (1972).

126 D. Weiss. Chem. Listy 66, 858 (1972).

127 G. Hermann. Ger. Patent No. 2064822 (1972). C.A. 77 096621s (1972).

128 H. Komiya. Bunseki Kagaku 21, 911 (1972).

129 M. S. Frant, J. W. Ross and J. H. Riseman. Anal. Chem. 44, 2227 (1972).

130 M. K. Pápay, K. Tóth and E. Pungor. Ion Selective Electrodes, Akadémiai Kiadó, Budapest, 1973 , p. 225.

131 R. N. Heistand and C. T. Blake. Mikrochim. Acta (Wien) 212 (1972).

132 R. Niklas-Salminer. J. Soc. Leather Trades Chem. 56, 139 (1972).

133 G. G. Guilbault, W. F. Gutknecht, S. S. Kuan and R. Cochran. Anal. Biochem. 46, 200 (1972).

134 C. Harzdorf. Z. Anal. Chem. 262, 167 (1972).

135 R. Jasinski and I. Trachtenberg. Anal. Chem. 44, 2373 (1972).

136 J. O. Goertzen and J. D. Oster. Soil. Sci. Soc. Amer. Proc. 36, 691 (1972).

137 C. Liteanti. I. C. Popescu and V. Ciovirnache. 3rd Conf. Natl. Chim. Anal. 1, 241 (1971).

138 J. Vrbsky and J. Fogl. Chem. Prum. 22, 241 (1972).

139 F. Tobias. Galvanotechnik 63, 644 (1972).

140 C. G. Lamm, E. H. Hansen and J. Růžička. Anal. Letters 5, 451 (1972). 